\section{Is magnetic fusion heading for ignition or meltdown?}

Physicists have long been keen to harness the energy of thermonuclear fusion. The next planned step is a major international project to build an experimental reactor, ITER. But the project has recently been running into a quagmire of technical, economic and political uncertainties that will require all the efforts of its supporters to overcome.

F or 50 years, researchers have sought to improve their understanding of how man could capture the power of fusion, the energy source of the Sun and all other stars. Their quest reaches a historic turning point next year, when the leading industrialized countries are due to decide if, when and where to construct the International Thermonuclear Experimental Reactor (ITER), a US\$10 billion testbed for the physics and engineering of magnetic confinement fusion.

For most of the past half-century, the favoured approach among fusion researchers has been the magnetic confinement of a fast-flowing loop of hot, ionized gas - or plasma - circulating in an evacuated, doughnut -shaped chamber called a tokamak. But there are many alternative approaches, and serious doubts persist about the feasibility of the tokamak concept which ITER will embody.

After billions of dollars of international investment in tokamaks, the best machines that have been built produce, at most, onethird of the energy that they consume. ITER is intended to break new ground not only by generating more power than it consumes, but by addressing some of the immense engineering challenges of operating a tokamak on a continuous basis.

The reactor vessel of such a tokamak would have to survive intense neutron irradiation from the burning plasma, while transferring heat out of the plasma at an unprecedented rate. When its structure is eventually destroyed by the neutrons, it would have to be replaced on a modular basis, by remote control.

Some scientists and engineers from outside the fusion field see such problems as insurmountable. They point to the debilitating effect of a constant flux of highly energetic $(14 \mathrm{MeV})$ neutrons on the tokamak chamber, and to the geometrical difficulties of transferring heat rapidly from the chamber to a coolant which would surround but not penetrate the reactor vessel.
Fusion advocates have long sought the construction of a special, high-energy neutron source to test the materials that a working fusion plant would require. But, they say, even without such a facility, materials researchers have been able to establish that vanadium and some steel alloys hold promise for use in such an environment.

"A number of the results have been very promising," says Bob Conn, dean of engineering at the University of California at San Diego. "When someone says it would be impossible, I don't think they know the data." He also believes that the heat transfer rate expected to be required at the edge of a tokamak - around $1 \mathrm{MW}$ per square metre — is achievable. "Many systems today operate at many times that," he says.

Just as difficult to contend with are the environmental and licensing problems that

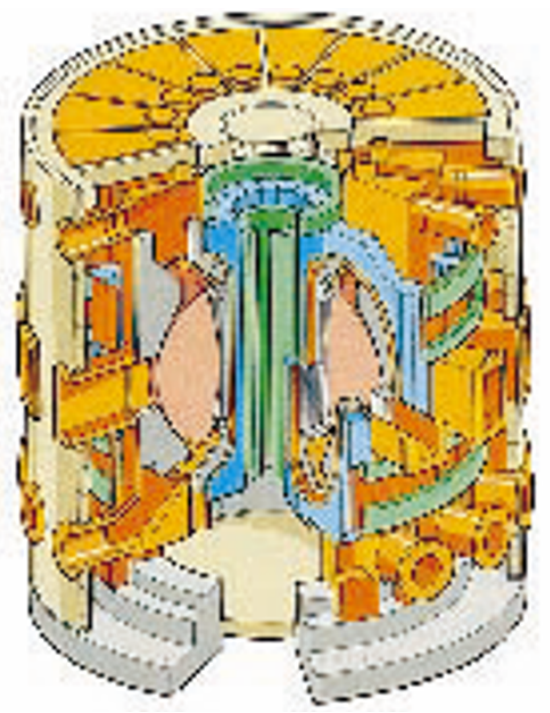

Vital statistics: the design of the proposed ITER tokamak envisages a reactor measuring 16 metres across, with a plasma current of $24 \mathrm{MA}$, fusion power of $1.5 \mathrm{GW}$, toroidal field of $5.7 \mathrm{~T}$ and a burn time of 1,000 seconds. would surround the construction of a fusion-based power plant. Although it would produce no high-level nuclear waste, a fusion plant would produce intermediate and low-level waste, particularly when decommissioned, and it would incorporate new and untested technologies. The construction of such a plant might well encounter fierce public opposition.

But fusion advocates say that such issues, however daunting, must be tackled if man is to gain access to an energy source that could meet the needs of a future global population of 10 billion. "One-hundred-and-fifty years ago, equally insurmountable difficulties could have been identified when contemplating heavier-than-air flight," one correspondent wrote to Physics Today in May. "One is glad now that Osborne Reynolds, Ludwig Prandtl, N. Joukowski and the Wright brothers didn't give up."

When they started the engineering design assessment phase of the ITER project in 1992, the four partners - Europe, Japan, Russia and the United States - agreed that they would make a firm decision about its construction by July 1998 . But, as governments face the need to control public spending, it has become apparent that they will not be ready to start building then. Through an informal group called the ITER Explorers, the partners are now looking at how to delay construction without draining the programme of momentum.

\section{Budget cuts bite}

Since 1995, when the Congress cut the budget for magnetic fusion research from $\$ 360$ million to $\$ 240$ million, it has been clear that the United States would not play a major role in building the experimental reactor. Last year, the best hopes for construction in Europe evaporated (see page 119). But the really bad news for the project came last month, when budget pressures in Japan led to a pledge that the Treasury would fund no major new scientific projects for three years (see page 116).

Serious international collaboration on magnetic fusion began at an Atoms for Peace conference in Geneva in 1958, when physicists at secret nuclear weapons laboratories in the United States and the Soviet Union exhanged notes on the peaceful use of fusion power. After the Second World War, as both countries raced to develop the fusion-based hydrogen bomb, their weapons scientists had sought means of harnessing the energy released when either the two nucleii of the hydrogen isotope, deuterium, or one atom of deuterium and one of tritium, are made to fuse together.

The key to the problem is the successful 
confinement of deuterium or deuterium -tritium plasma while it is heated to 100 million ${ }^{\circ} \mathrm{C}$ or more - temperatures at which any physical containment material would vaporize. Scientists have pursued two approaches to this: magnetic confinement fusion, which relies on magnets to confine the plasma, and inertial confinement fusion, which compresses and heats a small amount of fuel in situ, giving it nowhere to go but inwards on itself.

The hydrogen bomb is an uncontrolled inertial confinement fusion device, compressed by a fission-based nuclear explosion. Weapons scientists have worked for more than 30 years to build a controlled device, to help them with their weapons simulations. In the United States and France, major efforts are under way to do this with powerful laser beams. But such lasers take hours to cool down after one 'shot', and an inertial fusion machine for power generation would more probably be driven by an accelerated beam of heavy ions.

\section{Magnetic attraction}

Magnetic confinement fusion, in contrast, had little military value, but apparent potential as the core of a continuous power generation process - if it could be achieved and sustained. Various schemes were proposed to contain plasma magnetically, and in the late 1960s Soviet physicists persuaded their colleagues in the West that their concept of a tokamak was the most promising one.

Scientific collaboration continued as experimental tokamaks were built around the world, for example at Princeton University in the United States, at the Joint European Torus (JET) at Culham in the United Kingdom, and JT-60 in Japan. In these, scientists gradually raised the temperature of the plasma and the amount of fusion energy produced. The collaboration culminated in the launch of the ITER project at the first summit meeting between the then US President Ronald Reagan and Mikhail Gorbachev, in Geneva in 1985.

Europe and Japan joined the project at once, allowing it to absorb their own respective plans to build larger tokamaks, while political and economic turmoil in the Soviet Union curtailed its financial contribution (although scientific involvement from Russia remains robust today). Unable to agree on a location for a single central laboratory, ITER divided its workload between three 'home teams' at Garching in Germany, San Diego in California, and Naka in Japan.

\section{Partners follow different paths}

The outcome of the project's six-year engineering design assessment has inevitably become a compromise between the interests of different partners, reflecting differing views of what the machine should aim to achieve. Broadly, the United States had (and still has) a science-orientated fusion programme, and wanted a scientific experiment to enable the study of plasma at states known as 'burn' and 'ignition'.

In fusion of deuterium and tritium, fourfifths of the energy is released as neutrons and one-fifth is available as alpha particles, to reheat the plasma. If a tokamak's fusion 'gain' - heat out divided by heat in — reaches a value of five, the alpha heating will match the heat in, and the plasma is said to 'burn'. At ignition, the burn becomes self-sustaining, and no heat input is needed, so the gain is infinite. In a working fusion reaction, some energy would always be fed in to drive and control the plasma, and the gain would be about 25

The Japanese and Europeans had more immediate worries about energy supply than the Americans, and a greater inclination to spend public money on large technology development projects. They have been seeking a testbed for important fusion technologies, including new materials and efficient, superconducting magnets.

Many US critics continue to contend that ITER is the wrong machine. Two years ago, the President's Council of Advisors on Science and Technology (PCAST) argued that the partners should reconsider the project and try to build something smaller (see Nature 377, 567; 1995). The other partners rejected this proposal out of hand. "I'm confident that the machine we propose strikes the right balance between risk and meeting our objectives," says ITER's director Robert Aymar.

The criticism might have been contained if the US fusion programme had enough resources to pursue new experiments other than ITER. But it does not: magnetic fusion research has been under siege in the United

\section{Japanese industry fights budget setback}

Japanese hopes of hosting the ITER reactor received a severe setback last month from a budget reform plan that puts a ban on inviting the project to the country during the next three years (see Nature 387, 643; 1997). Proponents of the project in Japan still want the reactor to be sited there, but the reform plan has triggered public debate about the country's broader commitment to fusion research.

The budget reform has long been in the making, and underlines the fact that 'big science' projects face growing opposition from the powerful finance ministry. It follows a policy document on financial reform, published last year, which advocated a shift from large-scale - and often inefficient - public research and development efforts towards more flexible project funding, with a focus on research in universities.

The ITER project is said to have been raised during discussions at the ministry's advisory committee on public finance at the end of last year. This committee's recommendations are said to have been influential in setting the pace for the budgetary reform advocated by prime minister Ryutaro Hashimoto last month.

Despite the budgetary uncertainties, officials at the Science and Technology Agency (STA) who oversee ITER-related activities in Japan say the project is "inevitable" for the country's long-term energy prospects, and an "important opportunity" for Japan to immerse itself in large-scale international research collaboration. Past Japanese efforts in international cooperation in research, including the Human Frontier Science Projects, have only been partially successful.

The fact that the United States has considerably reduced its commitment to the experimental reactor has enhanced Japan's interest in the project, for those who feel that it may reduce the risk of the project becoming entangled in political tensions. But Japanese officials admit that they have only limited experience of cooperating with Europe.

The STA, which recently came under severe public criticism for its handling of the Monju fast-breeder reactor accident (see Nature 386, 209; 1997), has another reason for promoting ITER. Almost all Japanese research on tokamak fusion has been done by the Japan Atomic Energy Research Institute, a national research centre overseen by the STA and employing more that 1,600 researchers.

But over the last two decades, the institute has come under increasing pressure from more powerful organizations - such as the Power Reactor and Nuclear Fuel Development Corporation, which is now responsible for most of Japan's nuclear energy research - as well as the private sector. According to some observers, the institute is in considerable need of an overhaul and a new lead project such as ITER.

The proposed fusion reactor has influential supporters in Japanese industry. Hitachi, Toshiba and Mitsubishi Electric all prime contractors to the nuclear industry - have been developing expertise in fusionrelated technologies since the early 1980s, and they expect to win important engineering contracts if the project is built in Japan.

Last February, Keidanren, an organization made up of the chairmen of major Japanese industrial groups, set up a Forum for the Promotion of ITER to lobby 
States. It has been attacked by budget hawks, advocates of renewable energy, proponents of continued reliance on fission energy and by the physics community itself.

The black art of plasma physics - which is rather like the famously difficult study of turbulent flow, only tougher — has been treated with suspicion by many mainstream physicists. "It is very empirical, and you can't always do it from first principles. That causes a problem with other physicists," says Anne Davies, head of fusion research at the US Department of Energy (DoE). She talks of a "chasm" between fusion science and the rest of physics.

But it is the hype that surrounded fusion, particularly in the aftermath of the 1973 energy crisis, that has alienated many scientists. "There is ill-feeling from many other fields of study," says Richard Hazeltine, director of the Institute for Fusion Studies at

the government to bring the reactor to Japan.

Until recently, criticism of ITER was largely restricted to local anti-nuclear groups and citizens' movements in areas such as Tomakomai and Hokkaido, which are widely discussed as possible sites for the reactor. But influential voices are now joining the critics, including the country's largest newspaper, Yomiuri Shimbun.

Last December, in an attempt to provide a broad political platform to discuss options in regard to ITER, the Atomic Energy Council (AEC) set up another ITER Forum, bringing together the main stakeholders in the project and the representatives of various social groups. A report of its discussions is due to be published later this year.

These discussions are expected to provide guidance and advice on the practicalities of and conditions attached to a Japanese initiative to host the reactor. But a political decision on whether the project will be invited to Japan may still be several years away. As the AEC has no budgetary authority, financial questions will not be addressed by the forum, even though budgetary constraints are likely to be a key issue in the decision on whether to bid to host ITER.

Evaluations of the reactor's detailed design report by US, European and Japanese experts all suggest that present cost estimates may be over-optimistic. Critics in Japan say that the high construction costs in the country's nuclear industry may push total costs even higher, perhaps doubling the present most widely quoted estimate in Japan of $¥ 840$ billion (US\$7.3 billion).

Officials at the STA dismiss such estimates. But they admit that the cost issue

the University of Texas at Austin. He says that the fusion community has only itself to blame: "It is the result of us not being careful enough with our language when we advertise fusion. We should have been more careful in the things that we said."

\section{Doubts over design}

Even within plasma physics, ITER is not universally popular. Bruno Coppi, a plasma physicist at the Massachusetts Institute of Technology, has been predicting for years that the machine will not ignite, and advocating an alternative design - the Ignitor as a cheap and compact route to ignition.

But, as the US magnetic fusion budget has shrunk, there has been little money to develop alternatives to the tokamak. Competition between ITER and proposed US facilities, such as the now-

abandoned Tokamak

needs to be urgently readdressed on a site-specific basis. "We need realistic cost estimates and a site-
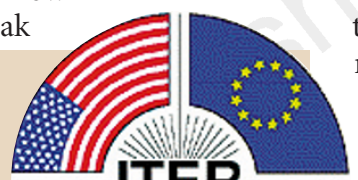
specific safety evaluation to judge whether we can express our intention to invite ITER," says Satoshi Tanaka, director of the office of fusion energy at STA.

But some fusion scientists in Japan, while supporting the project in principle, argue that the reactor's design is simply too expensive. "An overall design review with an eye to cost efficiency is a precondition for Japan to host ITER," says Atsuo Iiyoshi, director of the National Institute of Fusion Science (NIFS) and president of the Japanese Society of Plasma Science and Nuclear Fusion Research.

Others have been openly attacking ITER, arguing that Japan should take a more balanced approach to the development of future energy sources. Given the technological difficulties surrounding nuclear fusion, they argue that the parallel development of various design options would be a better strategy.

As an example of this approach, Japanese universities have already used education ministry funding to build an impressive series of helical fusion devices. In this design the plasma stream is confined by a system of helical coils, an approach that has been abandoned in most countries except Japan and Germany.

The world's largest helical fusion device, the Large Helical Device - with a magnetic field of 30,000 Gauss - is being completed at NIFS. But the budget for helical fusion has been only a fraction of what has been spent on tokamak fusion.
Physics Experiment, has also taken its toll on US support for the international project.

Last year, new doubts about the technical integrity of the design surfaced. A physicsbased model of plasma turbulence, developed by William Dorland and Michael Kotschenreuther of the Institute of Fusion Studies at Austin, suggested that ITER would not ignite (see Science 274, 1600; 1996). This assessment damaged ITER politically, according to several fusion scientists, but it helped plasma physics by spurring the investigation and application of such models. Dorland and Kotschenreuther are now working in the ITER project although, as Dorland notes, "this is not to say that they accept our results".

In fact, preliminary work with other supercomputer-based models of hot plasma is being cited by ITER advocates as refuting the research by Dorland and Kotschenreuther. According to Marshall Rosenbluth, a former member of the plasma physics department at the University of California at San Diego and now with the ITER Joint Central Team, this work suggests that the turbulence effects predicted by the Texas team will reach a saturation point, reducing by a factor of eight the rate of heat loss from the plasma that they predicted.

Where the Texan research models the plasma as a fluid, the new models simulate the kinetics of up to 100 million plasma ions directly, on a particle-by-particle basis. These models have been developed by Andris Dimits at Lawrence Livermore National Laboratory in California and Richard Sydora at the University of California at Los Angeles.

\section{Plasma problems pinpointed}

The DoE has established a regular, informal forum to discuss and attempt to resolve these issues. An April assessment of the current ITER design by the Fusion Energy Sciences Advisory Committee (FESAC), which advises the department on its fusion programme, said that uncertainties over plasma physics made it difficult to judge whether the reactor will confine plasma well enough to meet its design goals.

Conn, dean of engineering at the University of California at San Diego and lead author of the study, believes that the machine should still be built. "You can't guarantee anything - that's why it's an experiment," he says. The study said that the reactor's fusion gain (Q) could fall anywhere between foura serious disappointment - and infinity. "We have good confidence that Q will reach a value greater than 10," says Conn.

In the United States - where the likely foreign support for the project has sometimes been overestimated - the news that Japan, as well as Europe, are seeking to delay construction has been received badly. Until recently, for example, Hazeltine says he was 


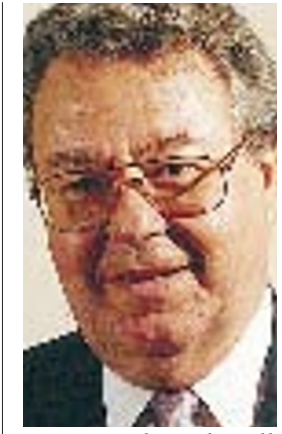

confident that the experimental reactor would be built, one day. Asked whether he still believes this, he says: "No, I do not. I knew there were reservations in the United States but, when I learned that Europe and Japan were ready to delay construction, Aymar: tokamak still I took that to be an the best research bet. ominous indicator."

But supporters of the project continue to talk up the prospects. "I do believe that ITER will go forward," says the DoE's Davies. John Sheffield, chair of FESAC and a physicist at Oak Ridge National Laboratory in Tennessee, points out that a comparable delay preceded the construction of the JET by the member states of the then European Economic Community, and could be "quite helpful" in finalising the design.

But many other observers, inside and outside the programme, doubt that ITER could survive such a hiatus. In the United States, money could be hard to find for continued collaboration on design work if the

construction is subject to doubt. In recent informal discussions, the United States has insisted that any extension to the engineering design assessment should end after two years unless there is a firm commitment to construction. "We insist that this will not be open-ended," says Davies.

Open-ended or not, the extension is set to reinforce a growing split between the partners over their approaches to the project. The United States, which has said that it will not host the reactor, will use the delay to complete research which slowed down during the engineering design assessment, as the US contribution to ITER fell from $\$ 80$ million in 1995 to $\$ 55$ million this year. Europe and Japan are expected to use the extension to do site-specific design and to negotiate with licensing authorities about possible sites.

But, even as construction is delayed, none of the partners wants to pull the plug on an international collaboration that has probably run as long and as deep as that in any science discipline. Indeed, the scientific collaboration itself is a major reason why political supporters of the project, such as George Brown, the senior Democrat on the Science Committee of the House of Representatives, stand by it. "I thank it will be built," he says.

\section{Rivals that might oust the tokamak}

If ITER is built, it will be the culmination of a 30-year period in which the Soviet idea of a torus-shaped, current-carrying ring of plasma, called a tokamak, has been the leading candidate to harness fusion power. If ITER collapses, alternative devices are poised to re-emerge as rivals to the tokamak.

Germany and Japan continue modest development programmes for the oldest such device, the stellarator. Sometimes known as a helical-fusion device, or heliotron, the stellarator looks and operates like a tokamak. But, where the tokamak relies on a current running through the plasma itself to induce the desired magnetic field, the stellarator uses an external, helical coil to induce the field.

In the United States, research on stellarators and other ideas for magnetic fusion - including the Elmo Bumpy Torus developed at Oak Ridge National Laboratory in Tennessee - has been squeezed out over the past decade as the fusion programme has shrunk from its peak of $\$ 470$ million in 1984 (worth more than $\$ 700$ million in today's money) to $\$ 240$ million today.

The only such idea still being pursued is the \$25 million National Spherical Torus Experiment, a tokamak tightly compressed into the shape of a sphere, being built at Princeton Plasma Physics Laboratory in New Jersey (see Nature 386, 313; 1997).

Some scientists advocate a compact but powerful tokamak aimed at the single goal of achieving ignition. Bruno Coppi of the Massachusetts Institute of Technology continues to seek government support in the United States and in Europe for such an experiment, which he calls the Ignitor.

But the most politically viable alternative to the tokamak is the entirely distinct approach of inertial confinement fusion (ICF), in which a tiny pellet of deuterium and tritium fuel is compressed and heated to produce a small, controlled thermonuclear explosion. The US nuclear weapons programme is about to spend $\$ 1.2$ billion to build the National Ignition Facility (NIF) at Lawrence Livermore National Laboratory in California, which will use the world's largest laser beams to do just that.

But the lasers will take hours to cool after one 'shot', and any ICF-based power plant would be more likely to rely on an accelerated beam of ions to heat the target. The US Department of Energy non-weapons fusion programme spends $\$ 7$ million a year studying such ion drivers. The scientists involved want $\$ 100$ million to build an ion accelerator to develop the idea. They say that such a facility, plus success at NIF, could open the way for the development of inertial confinement fusion as an energy source.

In an ICF power plant, they imagine, the targets would drop freely in a waterfall of liquid metal coolant, which would seamlessly absorb heat, neutrons and blast as they were 'shot' by the accelerator.
But Brown's confidence will have to spread to others if the sums are to add up. Partners used to assume that construction costs would be split under a so-called " $n+1$ " formula, with costs divided evenly but the host paying one extra share. When there were four partners, the split would be 40-20-2020; when it became apparent that Russia was out, the split became 50-25-25. Now that the United States has backed off, all bets are off.

According to Davies, Japan has said informally that it will only pay half the costs as host, dashing earlier hopes that it would pay up to 70 per cent. The United States might contribute 5 per cent and the Europeans, according to Davies, have indicated that if the reactor is built in Japan they will not pay more than the United States. So how can it be built? "They might find some other partners," suggests Davies.

\section{ITER weighed in the balance}

President Bill Clinton has recently asked his council of advisors on science for what is expected to be a landmark review of strategic US energy research. Physicist John Holdren of Harvard University is leading the study, which is due to be completed in October.

The nuclear component of the review is likely to weigh ITER against other options in magnetic fusion research. It may also compare magnetic fusion's prospects with those of inertial confinement fusion - which no impartial body has attempted to do, in the United States, since key elements of inertial confinement fusion were declassified in 1990 .

The fate of ITER and of magnetic confinement fusion research rests on how badly the industrial nations feel that they need a new, non-carbon emitting energy source. Confronted with low energy prices and public complacency over the issue, particularly in the United States, supporters of fusion are reduced to hoping that global warming will revive interest in strategic energy research.

Forty years after the public debut of magnetic fusion, its advocates have dropped their claims that it constitutes an easy route to a boundless energy supply. Today, their claims are more modest. "For the tokamak, I'd like to say what Churchill said about democracy," says Aymar. "It may look bad, but there is no other line of enquiry that would be better."

Asked if ITER will proceed, Sheffield expresses the mainstream US view: "It's obviously up to Europe and Japan," he says.

Balking at ITER's cost, the United States has passed the buck to the rest of the world. But like the US Congress, which is considering a modest restoration of fusion spending after recent sharp cuts, the rest of the world seems content to continue with fusion research as a kind of insurance policy without taking the plunge and agreeing to invest $\$ 10$ billion in building the experimental reactor.

ColinMacilwain 